\title{
Dynamization of external fixator is single stage definitive procedure for open fractures both bone leg
}

\author{
Ajeet Singh*, Rakesh Kumar, Rajni Ranjan, Avijit Mahajan
}

Department of Orthopaedic, School of Medical Sciences and Research, Greater Noida, Uttar Pradesh, India

Received: 25 July 2017

Revised: 01 September 2017

Accepted: 04 September 2017

*Correspondence:

Dr. Ajeet Singh,

E-mail: ajeet01doc@gmail.com

Copyright: () the author(s), publisher and licensee Medip Academy. This is an open-access article distributed under the terms of the Creative Commons Attribution Non-Commercial License, which permits unrestricted non-commercial use, distribution, and reproduction in any medium, provided the original work is properly cited.

\begin{abstract}
Background: Open fracture both bone leg is a common fracture present in orthopaedic causality. Treatment consists of I. V. antibiotics, debridement and external fixator. Judicious selection of the patients on basis of Gustilio and Anderson classification leads to external fixator as a definitive and single stage procedure with dynamization. It reduces the risk of infection at time of definitive procedure and number of hospital stay and surgery.

Methods: In school of medical sciences and research, We treated 68 patients with open both bone fracture (Gustilio and Anderson type 2 and $3 \mathrm{~b}$ ) with debridement and external fixator. All patients underwent dynamization depending upon fracture pattern. Majority of our cases were road traffic accident involving male. Average duration of union was 22 to 26 weeks. There was no need for any major plastic surgery procedure. Removal of external fixator and Patellar tendon brace (PTB) was given for the period of 4 to 6 weeks at the time of clinical and radiological union.

Results: Eighty eight percent of our cases united well. This reduces the burden of secondary definitive procedure, infection and cost of treatment. So careful selection of the patients and dynamization of external fixator hold the place for definitive surgical option for open both bone fractures.

Conclusions: External fixator is simple effective surgical procedure for open fractures both bone leg. Staged dynamization of external fixator add in the better union with functional outcome and cost effective.
\end{abstract}

Keywords: Open fracture, External fixator, Dynamization, Debridement, PTB

\section{INTRODUCTION}

Fracture both bone leg is one of the most common fracture encountered in orthopaedic emergency. As the subcutaneous presence of the tibia shaft, tibia is one of the most common sites for an open fracture. ${ }^{1}$ The usual protocol for any fracture is to stabilize the patients, for open fracture initial debridement of the wound and fracture management in the form of external fixation. ${ }^{2}$ Next step is in the form of definitive fixation reaming interlocking nail once healing of the wound. ${ }^{2}$ Main drawback of the procedure is need for several surgical procedure and longer hospital stay. The chances of infection in reamed interlocking nail post external fixator in open fracture is much more higher than closed fracture so it clearly indicate that delayed intramedullary nail in open fracture put patients on higher risk of infection and multiple procedure. ${ }^{3-5}$ Our main aim is to convert a temporary procedure in to a definitive one with single stage and avoiding economic burden on poor patients. Flexibility of placing pins make external fixator an effective tool in case of open fractures, especially type 3 Gustilio and Anderson. ${ }^{6}$ The simplicity of the procedure does not require steep learning curve and short procedure time make it perfect for poly trauma patients. Monoframe with sufficient space and flexibility of pin placement makes it suitable for complex plastic surgical procedure. ${ }^{7}$ AO external is a simple device that consists of tubular 
rod, schanz pin, clamp and double clamp that provide rigid fixation.

\section{Objective}

To analyze the efficacy of dynamization in external fixator for the treatment of open both bone fracture leg.

\section{METHODS}

In School of medical sciences \& research April 2013 to January 2017, we treated 103 cases of open both bone fracture out of which 68 cases with type 2 and type $3 a$ selected for study. There were 57 male and 11 female, most of them were working class in their 20 to 40 and most common mode of injury was road traffic accident, 14 were fall from height as we are surrounded by lots of progressing construction work, only one case of assault. Complete physical examination was done to rule out any organ injury. First dose of prophylactic antibiotic cephalosporin along with aminoglycosides administered and tetanus toxoid with tetanus immunoglobulin give in the emergency department. After hemodynamic stabilization primary wound debridement with large amount of normal saline done with classification according to Gustilio Anderson classification as type 1, 2, 3 and $3 a, 3 b, 3 c$ to be more precise to determine the rate of infection. We included compound diaphysial both fracture with Gustilo Anderson type 2 and type 3a. The important consideration made during surgical procedure was pin placement that it should be well away from wound with sparing of joint. Post op x-ray taken and subsequent follow up X-ray taken on 4 to 6 weeks duration. Out of 68 patients 8 required skin grafting and 7 patients required secondary skin closure. Most of our early secondary procedure performed within a week. Dynamization was performed by loosening the $\mathrm{A} O$ clamp screw attached A O tubular rod on side of short fragment. Dynamization of transverse and oblique fracture performed at 4 to 6 weeks and comminuted fractures done on 6 to 8 weeks. Post dynamization partial weight bearing allowed depending upon patient tolerance. Consecutive follow up x-ray taken during 4 to 6 weeks follow up, with average duration of external fixator was 22 to 26 weeks. Once there was clinical sign of union present like no mobility and radiological callus, removal of external fixator and patellar tendon brace application for 4 to 6 weeks. Five cases showed no radiological signs of union by 16 weeks, removal external fixator and illizarov application, bone grafting and acute docking performed. Three cases managed with reamed tibial inter medullary interlocking nail and bone grafting.

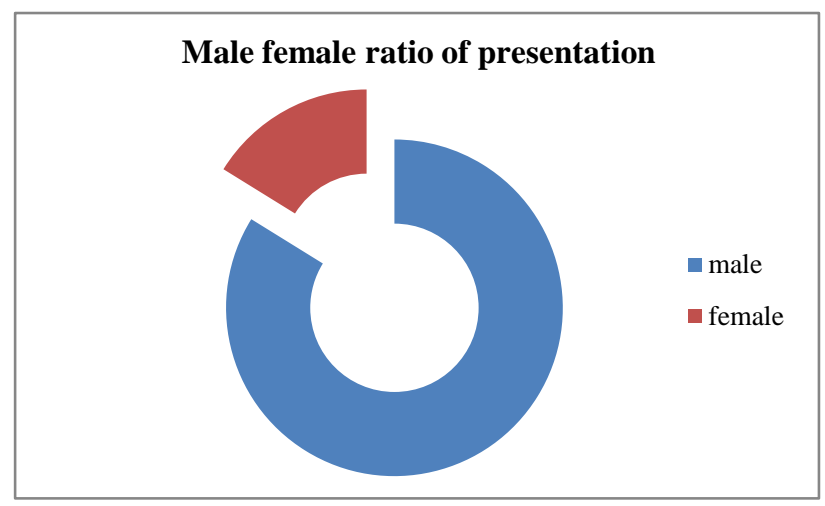

Figure 1: Ratio at presentation.

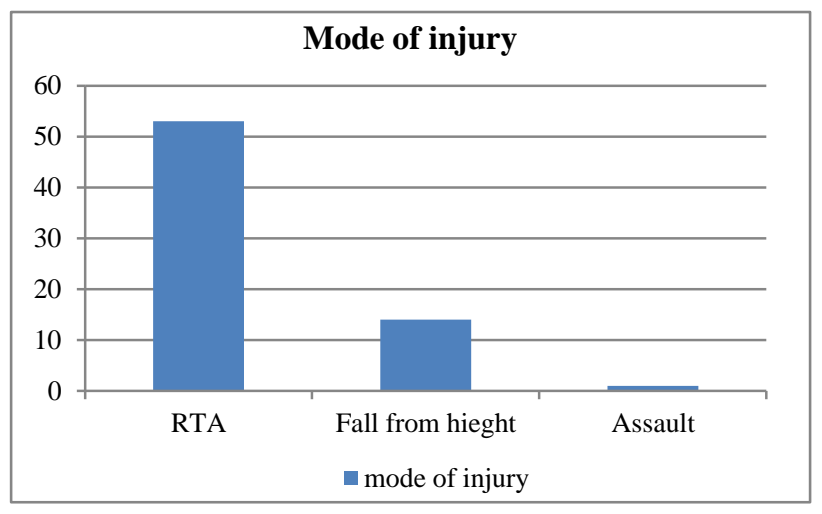

Figure 2: Mode of injury.

Table 1: Gustilio and Anderson classification of open fractures.

\begin{tabular}{|ll|}
\hline Classification & Description \\
\hline \multirow{3}{*}{ Type 1 } & Puncture wound of less than or equal to $1 \mathrm{~cm}$ with minimal soft tissue injury. \\
\hline \multirow{3}{*}{ Minimal wound contamination or muscle crushing. } \\
\hline \multirow{3}{*}{ Type 3a } & Wound is greater than $1 \mathrm{~cm}$ in length. \\
\hline & Soderate soft tissue injury. \\
\hline \multirow{3}{*}{ Type 3b } & Coft tissue coverage of bone the bone is adequate. \\
\hline Extensive soft tissue damage. \\
\hline Type 3c & Soft tissue coverage of the bone is adequate. \\
\hline
\end{tabular}




\section{Inclusion criteria}

Inclusion criteria were Gustilo and Anderson type 2 and type $3 \mathrm{a}$.

\section{Exclusion criteria}

Exclusion criteria were fracture with Gustilio and Anderson type 3b, 3c; fracture with bone defects; intra articular fractures; associated fracture shaft of femur.

\section{RESULTS}

In our study 68 cases of open both bone fracture with Gustilio and Anderson type 2 and $3 \mathrm{a}$ included. The patients were 20 to 62 years of age out of which maximum number of cases were 20 to 40 years of age. 57 were male which shows outside activity put them on more risk. Road traffic accident was the main cause of injury followed by fall from height, and only one case of assault. 8 cases required skin graft and 7 cases required secondary skin closure. As it was only type 3 a included no complex plastic surgery was performed. 18 patients had superficial pin tract infection treated with antibiotic and pin site dressing. Three patients had severe osteolysis around the schanz pin with infection required change of pin position. Six patients had limb length discrepancy of $2 \mathrm{~cm}$ which was functionally well accepted. Eight patients had anterior angulations but less than 10 degree. Average duration of union in our study was 22 to 26 weeks. Five cases required illizarrov and three cases treated with reamed tibia IMIL. $88 \%$ cases united well with AO external fixator and judicial dynamization.

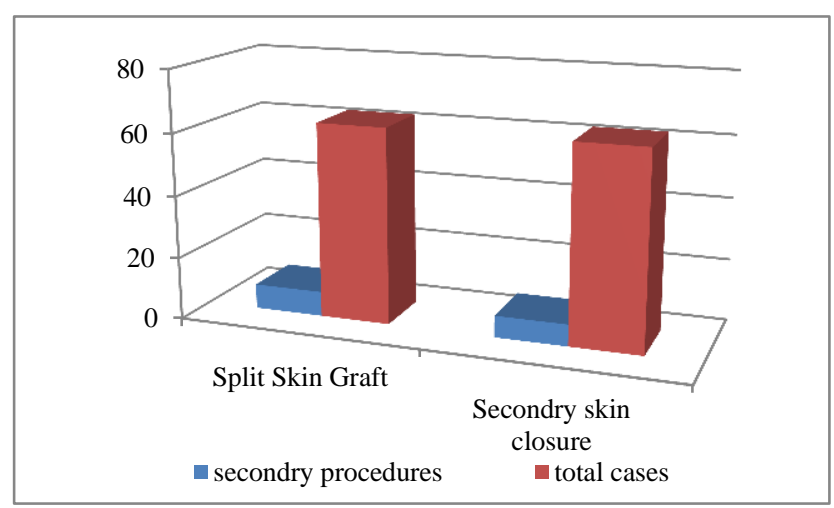

Figure 3: Secondary procedures.

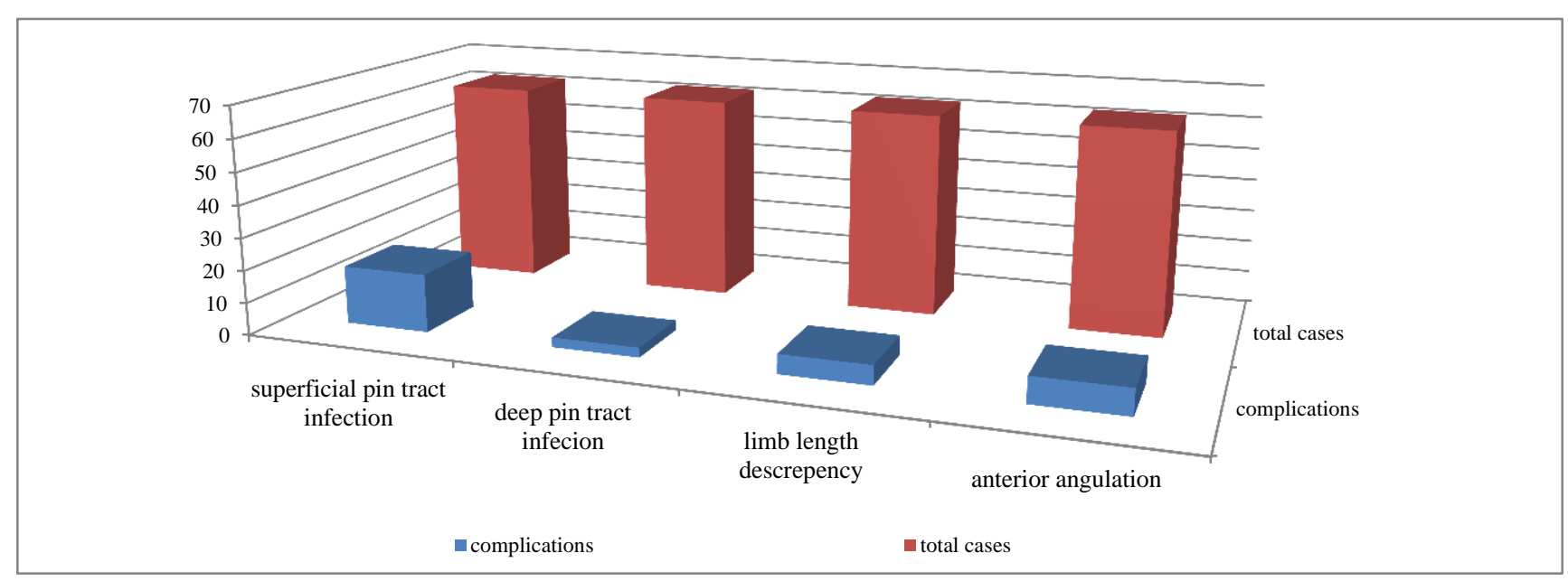

Figure 4: Complications.

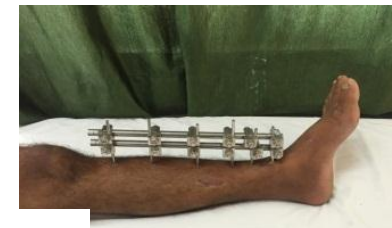

A

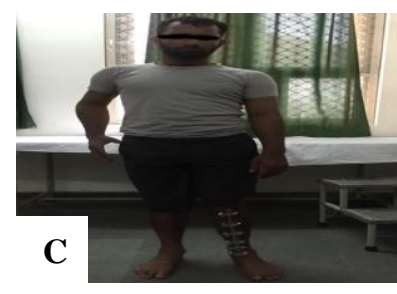

D

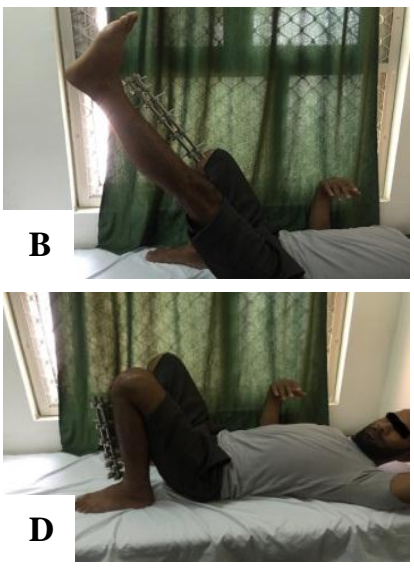

Figure 5 (A-D): Patient at the time of dynzmization with full range of motion and weight bearing.
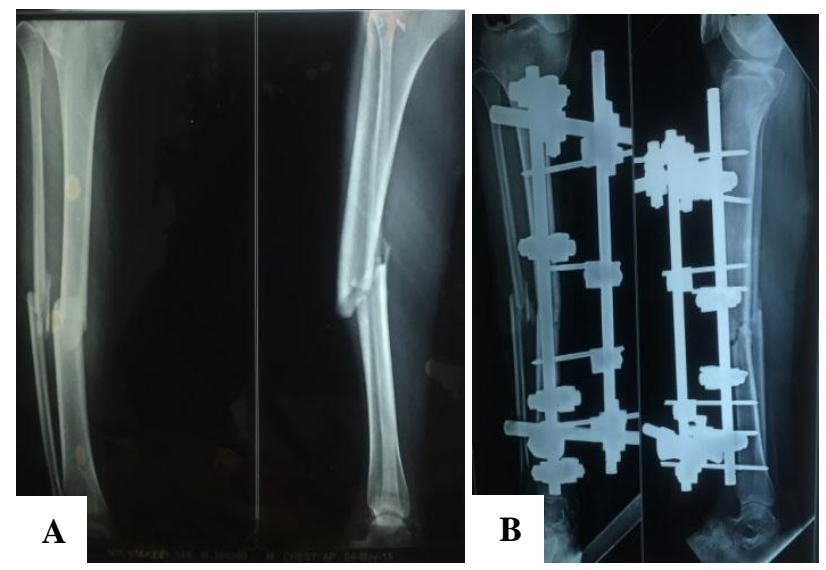

Figure 6 (A and B): X-ray at presentation x-ray postoperative. 

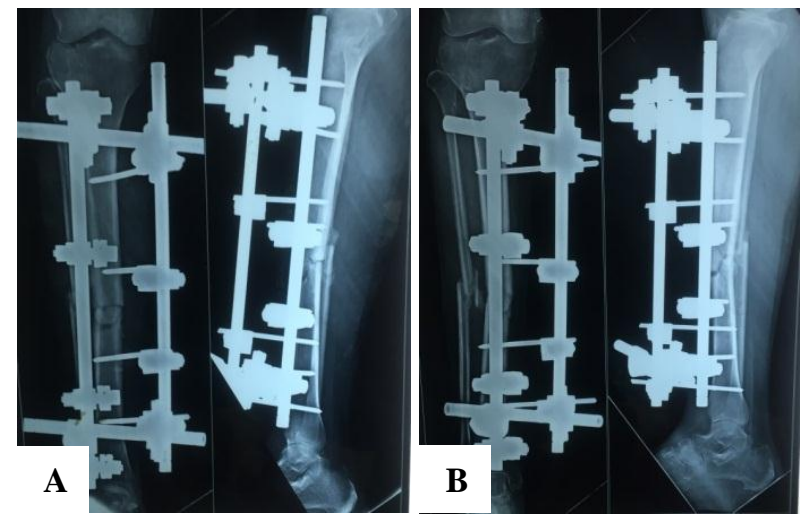

Figure 7 (A and B): X-ray at susequent follows up at 4 to 6 weeks duration pre and post dynamization.
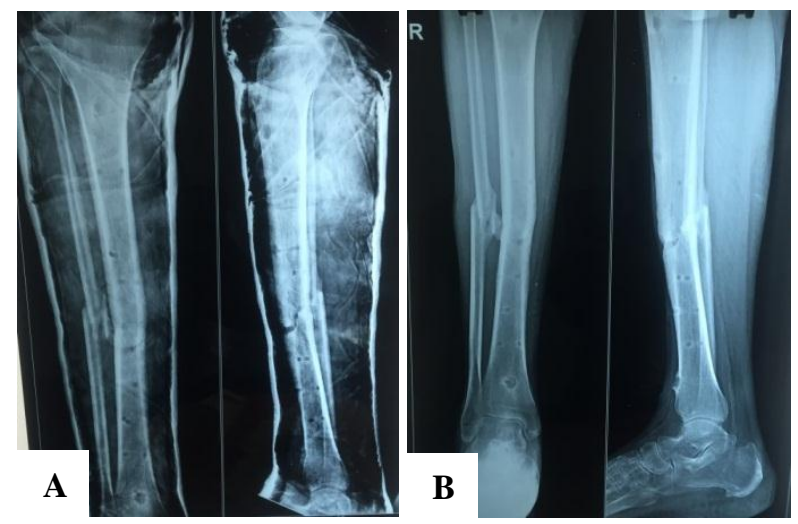

Figure 8 (A and B): X-ray at the time of PTB application $\mathrm{X}$-ray at clinical and radiological union.

\section{DISCUSSION}

External fixator was one of the popularized surgical options in mid- $20^{\text {th }}$ century when introduced by Hoffman, soon after that charnley popularized the knee arthrodesis by external fixator. ${ }^{8}$ External fixator causes less disruption of the soft tissue, periosteum and osseous blood supply that make it as savior in open injuries and compound fracture. ${ }^{9}$ Stiffness of external fixator can be increase by many methods, like controlling near and far fragments of each bone segment, decreasing the distance between rod and bone, increasing the number of connecting rods, increasing the diameter of the pins and using multiplanar fixation. ${ }^{8}$ That gives additional advantage to control the stiffness of the implant, which is required in the initial duration facture management. It is always advisable to put multiplaner frame to increase the stability of external fixator. ${ }^{10}$ For increase stiffness over the fracture callus early weight bearing with appropriate amount of motion over the fracture site is required. ${ }^{11}$ For a fracture to unite in external fixator combination of blood supply, bony stability and axial loading is necessary. ${ }^{12}$ One of the major concern is to defined proper guideline to convert from external fixator to IMIL nail, second is deep infection which was $17 \%$ with all preventive measure and with chronic osteomyelitis $2.5 \%{ }^{13}$ Only the combination of a sufficient blood supply, bony stability and the axial loading will provide the necessary environment for osteogenesis. External fixator (mono-planer and bi-planer) provide sufficient bony stability along with axial loading in case of weight bearing post dynamization. The geometry of the fracture or osteotomy gap will affect the stability. Good bony contact on the fracture site dramatically augments the frame stability and ability to weight bear. It was found in the study of Klein et al, that mechanical and histomorphometrical inferior bone healing in the Intra medullary nail in comparison to external fixator as external fixator is the only treatment modality in which such cyclical moment can be controlled with dynamization. ${ }^{14}$

\section{CONCLUSION}

External fixator is the best available option for open both bone fracture in initial hours. It provides both skeletal stabilization and environment for soft tissue healing. In our cases we selected patients where we can provide single stage procedure with economical affordable implant, with low deep infection. Need for second surgery is only indicated when there is paucity of callus formation on follow up X-ray.

Funding: No funding sources Conflict of interest: None declared

Ethical approval: The study was approved by the institutional ethics committee

\section{REFERENCES}

1. Whittle PA, Wood II GW. Fractures of lower extremity. 10th Ed. In: Campbell's Operative orthopedics, Canale TS, ed. Philadelphia: Mosby Publications; 2003: 2761-2767.

2. Blachut PA, Meek RN, O'Brien PJ. External fixation and delayed intramedullary nailing of open fractures of the tibial shaft. A sequential protocol. J Bone Joint Surg Am. 1990;72(5):729-35.

3. Reuss BL, Cole JD. Effect of delayed treatment on open tibial shaft fractures. Am J Orthop. 2007;36(4):215-20.

4. McGraw JM, Lim EV. Treatment of open tibialshaft fractures. External fixation and secondary intramedullary nailing. J Bone Joint Surg Am. 1988;70(6):900-11.

5. Maurer DJ, Merkow RL, Gustilo RB. Infection after intramedullary nailing of severe open tibial fractures initially treated with external fixation. J Bone Joint Surg Am. 1989;71(6):835-8.

6. Padhi NR, Padhi P. Use of external fixators for open tibial injuries in the rural third world: panacea of the poor? Injury. 2007;38(2):150-9.

7. Tornetta P, Bergman M, Watnik N, Berkowitz G, Steuer J. Treatment of grade-IIIb open tibial fractures: A prospective randomised comparison of external fixation and non-reamed locked nailing. J Bone Joint Surg Br. 1994;76:13-9. 
8. Fragomen AT. Rozbruch SR. The mechanics of external fixation. HSS J. 2007;3(1):13-29.

9. Claes L, Heitemeyer U, Krischak G, Braun H, Hierholzer G. Fixation technique influences osteogenesis of comminuted fracture. Clinorthop. 1999;365:221-9.

10. Gasser B, Boman B, Wyder D. Stiffness characteristic of the circular illizarov device as opposed to conventional external fixator. J Biomech Eng. 1990;112:15-21.

11. Klein P, Schell H, Strieparth F. The initial phase of fracture healing is specifically sensitive to mechanical condition. J Orthop Res. 2003;21:662-9.

12. Ilizarov GA. The Apparatus: components and biomechanical principle of application. In Green $S$ transosseus osteosynthesis. Theoretical and clinical aspects of the regeneration and growth of tissue. Springer - Verlag Berlin; 1992: 63-136.

13. Giannoudis P, Roberts C, Papakostidis C. A review of the management of open fracture of the tibia and femur. J Bone Joint Surg Br. 2006;88-B:281-9.

14. Klein P, Opitz M, Schell H, Taylor WR, Heller MO, Kassi JP, et al. comparison of undreamed nailing and external fixation of tibial diastases - mechanical conditions during healing and biological outcome. J Othop Res. 2004;22(5):1072-8.

Cite this article as: Singh A, Kumar R, Ranjan R, Mahajan A. Dynamization of external fixator is single stage definitive procedure for open fractures both bone leg. Int J Res Orthop 2017;3:1152-6. 